\title{
De la hipoteca al desahucio: ejecuciones hipotecarias y vulnerabilidad territorial en España'
}

\author{
Ricardo Méndez Gutiérrez del Valle²
}

\begin{abstract}
RESUMEN
Las ejecuciones hipotecarias promovidas por entidades financieras que pueden conducir al desahucio inmobiliario se han multiplicado en España desde el inicio de la crisis económica. El crecimiento del mercado hipotecario en un contexto de desregulación está en el origen de un proceso que ahora expulsa anualmente a miles de familias de sus hogares y refleja los fenómenos de desposesión asociados a las crisis capitalistas. El objetivo del artículo es analizar el crecimiento y la distribución espacial de las hipotecas y las demandas de ejecución hipotecaria presentadas por los acreedores en 2001-2014. Se basa en los datos publicados por el "Consejo General del Poder Judicial", que permiten conocer su evolución en ese periodo y muestran la profundización del desarrollo geográfico desigual. Los resultados confirman su mayor intensidad en los territorios que asumieron mayores riesgos por su especialización inmobiliaria y en las periferias metropolitanas donde residen los grupos sociales más vulnerables.
\end{abstract}

Palabras clave: Ejecuciones hipotecarias, desahucios, financiarización, vulnerabilidad territorial, España.

\begin{abstract}
Foreclosures promoted by financial institutions which can lead to housing eviction have multiplied in Spain since the beginning of the economic crisis. The growth of the mortgage market in a context of deregulation is at the origin of a process that now thousands of families from their homes annually and reflects the dispossession associated with capitalist crises. The aim of this paper is to analyze the growth and spatial distribution of accorded mortgages and foreclosures filed by creditors in 2001-2014. It is based on data published by the "General Council of the Judiciary", which allow its evolution over the period and prove the deepening of uneven geographical development. The results confirm its highest intensity in the territories that took greater risks for their real estate specialization and metropolitan peripheries where most vulnerable social groups live.
\end{abstract}

Keywords: Foreclosures, evictions, financialization, territorial vulnerability, Spain. 
"Los pequeños agricultores vieron cómo las deudas iban creciendo como la marea... El próximo año este pequeño huerto será parte de un gran conjunto, pues la deuda habrá ahogado al propietario. La viña pertenecerá al Banco. Sólo los grandes propietarios pueden sobrevivir porque también poseen las fábricas de conservas... Este es un crimen que no tiene nombre. Aquí hay una pena que el llanto no puede simbolizar. Hay aquí un fracaso que anula todos los éxitos" (John Steinbeck: Las uvas de la ira, 1939).

Los procesos de deterioro social e incremento de diversas formas de desigualdad provocados por la crisis económica iniciada en 2007 y profundizada por las políticas neoliberales de austeridad fiscal impuestas desde 2010 han tenido en España múltiples manifestaciones. Una de las principales ha sido el rápido y fuerte incremento de los procesos de desahucio de todo tipo de inmuebles -en especial viviendas- derivados en una parte considerable del impago de las deudas hipotecarias contraídas, origen de una intensa movilización social.

De este modo, el anómalo crecimiento del negocio hipotecario durante más de una década, promovido por las entidades financieras con el apoyo legal y fiscal de diferentes gobiernos, provocó una inusitada expansión, tanto de la construcción inmobiliaria como de los precios, que está en la raíz de un proceso que en los últimos años expulsa anualmente a miles de familias de sus hogares. El auge y la caída del mercado hipotecario son así parte de un mismo ciclo de acumulación y desposesión -un fenómeno inherente a la lógica capitalista que, como recuerda la cita de Steinbeck, se reproduce en momentos y lugares diversos- con implicaciones sociales evidentes, al tiempo que profundiza las tendencias al desarrollo geográfico desigual.

Por un lado, el grado de endeudamiento hipotecario en la fase expansiva del ciclo fue muy desigual según territorios y eso se refleja ahora en una distinta densidad y gravedad de los impagos, en función del riesgo asumido en cada caso. Por otro, la morosidad afecta en mayor medida a aquellos segmentos sociales más frágiles y precarios, por lo que los desahucios se concentran en aquellas áreas donde están más presentes. Eso permite hablar de una geografía de la desposesión, visible a diferentes escalas pero aún poco investigada en el caso español, cuya descripción e interpretación constituye un objetivo genérico de investigación que aúna la relevancia científica con la social.

El objetivo específico del artículo ha sido investigar el crecimiento y la distribución espacial tanto de las hipotecas constituidas como, sobre todo, de las demandas de ejecución hipotecaria presentadas por los acreedores en los juzgados de primera instancia, que ponen en marcha el proceso que puede finalizar con el lanzamiento o expulsión de quienes contrajeron en su día la deuda hipotecaria.

Las fuentes judiciales sobre ejecuciones hipotecarias, publicadas por el Consejo General del Poder Judicial, son por el momento las únicas que en España permiten obtener una panorámica de lo ocurrido desde el inicio de la última crisis y compararlo con los años previos, así como aportar una perspectiva de conjunto para todo el territorio español. Como contrapunto, carecen de información sobre el tipo de inmueble o las características de sus residentes, identifican las demandas presentadas pero no todas acaban en desahucio y no consideran los derivados del impago de alquileres, al tiempo que solo permiten descender en el análisis hasta los 431 partidos judiciales en que se subdivide a estos efectos el territorio español. En consecuencia, la investigación que aquí se presenta puede servir de marco a estudios de caso abordados con otro tipo de fuentes numéricas o mediante el uso de técnicas cualitativas.

El artículo aborda dos tipos de preguntas de investigación que se complementan, tres de ellas de carácter descriptivo: (i) ¿qué intensidad ha tenido el ciclo hipotecario en España desde comienzos de siglo?; (ii) ¿cómo se relaciona con la evolución registrada por las ejecuciones hi- 
potecarias?; (iii) ¿cómo se distribuyen espacialmente las presentadas desde el inicio de la crisis y hasta qué punto el mapa coincide con el de los territorios de la burbuja hipotecaria previa? En el plano teórico, se pretende vincular lo ocurrido en España con tres tipos de debates asociados a los procesos de urbanización neoliberal: (i) ¿en qué medida lo ocurrido materializa el impacto de la financiarización sobre el crecimiento inmobiliario descontrolado en determinadas áreas?; (ii) ¿cómo se relaciona con los procesos de acumulación por desposesión?; (iii) ¿qué claves internas o externas explican la desigual vulnerabilidad de los territorios a las ejecuciones hipotecarias?

El texto se inicia con una breve reflexión teórica sobre estos aspectos junto a una justificación de las fuentes y metodología utilizadas, destina lo esencial de su contenido a analizar la evolución y territorialización de las hipotecas constituidas y las ejecuciones hipotecarias presentadas, finalizando con algunas conclusiones que intentan dar respuesta a las preguntas planteadas.

\section{Financiarización, ciclo hipotecario y crisis: una perspectiva territorial}

\section{De la financiarización del crecimiento inmobiliario a la desposesión}

Uno de los rasgos estructurales que definen la actual fase de desarrollo capitalista es la consolidación de un régimen de acumulación financiarizado, que no solo supuso una expansión sin precedentes de los flujos de capital al margen de la economía real, de los productos y operadores financieros, una aceleración de procesos y la mundialización de los mercados, sino también la imposición de su lógica de funcionamiento al conjunto de actividades y territorios (Chesnais, 2003; Epstein, 2005; Stockhammer, 2010; Dumènil y Lévy, 2014), lo que otorga un carácter invasivo a lo que Marazzi (2009) identifica como "capitalismo gerencial financiero". La paralela desregulación de esos mercados y la lógica cortoplacista inherentes a la imposición de una racionalidad neoliberal capaz de impregnar múltiples aspectos de la vida individual y colectiva (Laval y Dardot, 2010) alimentó sucesivas "burbujas" de activos, seguidas de crisis financieras localizadas que culminaron en la de 2008, de dimensión ya global.

Las elevadas plusvalías generadas en los circuitos financieros encontraron un modo de inversión rentable en la producción de espacio urbano, alimentando un "circuito secundario de acumulación" que tuvo en el sector inmobiliario su principal exponente. La teorización sobre los dos circuitos del capital elaborada por Lefebvre $(1970,1974)$ y, más tarde, Harvey $(1975,1985)$ cuenta con abundante bibliografía (Aalbers, 2008; Gotham, 2009; De Mattos, 2016), de la que pueden recordarse tan solo algunas ideas centrales. En un contexto de beneficios decrecientes derivados de las actividades productivas y de servicios del primer circuito, la búsqueda de nichos de inversión con alta rentabilidad a corto plazo resultó clave para el desarrollo de ese segundo circuito pues, como había afirmado Lefebvre (1970: 165), "mientras disminuye la plusvalía global generada y realizada por la industria, aumenta la plusvalía basada y realizada en la especulación y mediante la actividad inmobiliaria". De ahí la creciente importancia otorgada al proceso de urbanización en la absorción y valorización de los excedentes de capital generados por la globalización financiera, que es donde pueden encontrarse las "raíces urbanas de la crisis" que sacudió al sistema a partir de 2007 (Harvey, 2012).

La paralela concentración de las empresas constructoras e inmobiliarias mediante fusiones, absorciones y participación cruzada de directivos en sus consejos de administración, junto a 
la multiplicación de operadores internacionales, otorgó a este tipo de coaliciones un creciente poder y capacidad de influencia sobre los diferentes gobiernos para retroalimentar esos mismos procesos urbanizadores (López y Rodríguez, 2010). Aunque los específicos ensamblajes o estructuras políticas e institucionales asociados a la trayectoria de cada territorio generaron formas de inserción específicas en la globalización neoliberal (Peck y Theodore, 2007), la simbiosis entre movilidad del capital financiero, conversión de suelo e inmuebles en bienes de inversión y mercantilización del desarrollo urbano se convirtieron en claves que sustentaron el modelo de urbanización neoliberal (Hackworth, 2007; De Mattos, 2007; Hidalgo y Janoschka, 2014).

Componente esencial en ese proceso de financiarización son unos mercados hipotecarios progresivamente desregulados, cuyo protagonismo en la creación de burbujas inmobiliarias de carácter especulativo y en su posterior crisis ha sido ampliamente investigado (Stephens, 2007; Aalbers, 2009; Reinhardt y Rogoff, 2009; Daher, 2013). Los créditos hipotecarios constituyen la forma habitual de acceso al mercado inmobiliario para la mayoría de la población y las empresas. Se pone así en marcha un proceso de endeudamiento cuya dimensión y riesgo se verá influido por factores como el volumen de capital disponible y las tasas de interés vigentes en los mercados, el nivel de apalancamiento permitido a las entidades financieras o las condiciones exigidas a los demandantes de crédito.

En un contexto de liberalización casi plena, con el consiguiente descontrol de los mercados financieros e hipotecarios, a lo que se unió la posibilidad de titulizar las hipotecas y convertir así en activos financieros móviles y negociables en los mercados esos bienes inmuebles, distribuyendo el riesgo hasta convertirlo en sistémico, se dieron las condiciones para la fuerte expansión del negocio hipotecario. En ese ambiente, la competencia por captar nuevos clientes propició la asunción de mayores riesgos por parte de muchas entidades respecto a las condiciones exigidas para acceder al crédito. Esa fase expansiva del ciclo hipotecario puede tener una duración variable, pero siempre acaba apareciendo cierta saturación del mercado de la vivienda o un aumento de la morosidad entre los deudores más frágiles si se modifican las condiciones del entorno (aumento de tipos de interés, caída del empleo o los ingresos...). Estos síntomas ponen en marcha una paralización del mercado hipotecario, a menudo brusca, al reproducirse esa sucesión de "manías, pánicos y cracs" bien conocida en toda crisis financiera (Kindleberger \& Aliber, 2005). Precisar, pues, la dimensión alcanzada por la espiral crediticia en cualquier territorio es condición necesaria para comprender tanto el origen de las "burbujas" inmobiliarias como los posteriores procesos de desahucio que son una derivada de lo anterior y pueden vincularse con los fenómenos de desposesión que provocan las crisis capitalistas.

En un texto muchas veces citado, al destacar "el papel continuo y persistente de las prácticas depredadoras" en los procesos de acumulación inherentes al sistema, Harvey (2004: 116) identificó estos últimos como de "acumulación por desposesión". El capital financiero y el sistema crediticio constituyen "palancas importantes de depredación, fraude y robo" (p. 118) y en tal sentido los procesos de endeudamiento masivo, propiciados por la financiarización imperante en las últimas décadas y sometidos a movimientos especulativos en unos mercados de capital desregulados, que escapan al control de los endeudados, serían una de sus principales manifestaciones. Aunque se trata de un proceso que permea la historia del capitalismo, alcanza sin duda su máxima intensidad en los momentos de crisis. Es entonces cuando la destrucción de capacidad productiva y empleo, la depreciación de todo tipo de activos (financieros, inmobiliarios) y del trabajo, la privatización de bienes comunes y públicos, junto a las transferencias de propiedad en perjuicio 
de quienes perdieron sus ahorros o han quedado atrapados en la trampa de la deuda, alcanza sus mayores cotas, lo que conduce a la ruptura del contrato social y al empobrecimiento de amplios sectores sociales. El estudio de los procesos de desahucio por impago de la deuda hipotecaria puede así entenderse en el marco de una tendencia estructural y cíclica más amplia, al tiempo que permite comprobar que el lugar importa cuando se evalúa la desigual intensidad alcanzada por esa devastación social.

\section{La desigual distribución de los desahucios hipotecarios y la vulnerabilidad territorial}

Tal como ha sucedido en todas las crisis capitalistas, los recientes procesos de desposesión concentraron sus efectos en grupos sociales y ámbitos territoriales específicos en función de su trayectoria previa y su perfil socioeconómico, acentuando así los procesos de polarización y fragmentación. El concepto de "vulnerabilidad territorial" resulta de especial utilidad para comprender por qué algunos lugares mostraron una especial fragilidad en tanto otros fueron más resistentes y vieron atenuados sus efectos.

Puede definirse como vulnerables a aquellos lugares con alta probabilidad de verse afectados de forma negativa por algún acontecimiento en función de dos tipos de razones que a menudo se complementan. Por un lado, una elevada exposición a riesgos de diversa naturaleza que escapan a su control; por otro, su escasa capacidad de respuesta, tanto por sus debilidades internas como por la falta de apoyo externo para atenuar los daños provocados. La vulnerabilidad territorial presenta algunas características específicas comenzando por su carácter relativo, pues todos los lugares son hasta cierto punto vulnerables pero en distinto grado y según el tipo de amenaza. Es también dinámica, pues aunque se asocia con frecuencia a problemas estructurales y persiste con el paso del tiempo, puede aumentar o disminuir en relación con decisiones y acciones acumuladas a lo largo de su trayectoria que profundicen su fragilidad o, por el contrario, la reduzcan. Es asímismo una construcción social o una incertidumbre fabricada, por lo que aquellos territorios que optan por modelos de crecimiento de alto riesgo, excesivamente especializados en lo económico, polarizados en lo social e insostenibles en lo ambiental, serán más vulnerables. Por último, es un concepto objetivo y mensurable, pero tiene también una dimensión subjetiva asociada a la percepción que los ciudadanos tienen del territorio donde viven (CEPAL, 2002; Alguacil et al., 2014; Subirats y Martí-Costa, 2014; Méndez, 2015).

Entendida así, la diferente vulnerabilidad de los territorios frente a las crisis capitalistas y, de modo específico, frente a algunas de sus manifestaciones con mayor impacto social como son los procesos de ejecución hipotecaria y los desahucios inmobiliarios puede interpretarse como resultado de su previa exposición al riesgo, los recursos tangibles e intangibles de que disponen sus residentes y las estrategias de respuesta emprendidas frente a esa amenaza, lo que vincula esta hipótesis interpretativa con los argumentos anteriores. En ese sentido, la racionalidad neoliberal, portadora de un "sentido común" que se difundió de forma progresiva, provocó la aparición de nuevas vulnerabilidades o el reforzamiento de otras preexistentes, aumentando los riesgos a que se exponen numerosas comunidades y territorios. La imposición de una lógica financiarizada a la producción de vivienda, convertida en bien de inversión progresivamente alejado de su función social, junto a la menor capacidad y voluntad del sector público para atenuar sus efectos, estarían en la raíz de ese incremento de vulnerabilidad. 
No obstante, si bien la creciente importancia alcanzada por el "circuito secundario de acumulación" es una tendencia generalizada, en aquellos territorios donde la apuesta por un desarrollo inmobiliario ilimitado, sustentado en estrategias hipotecarias de riesgo y en un endeudamiento insostenible a medio plazo sea mayor, la exposición al riesgo alcanzará sus mayores cotas. En bastantes casos ese proceso suele acompañarse de una progresiva "flexibilización" del planeamiento urbanístico, sustituido por una proliferación de proyectos que someten la gestión y ordenación del territorio a la hegemonía de determinados intereses particulares, lo que genera nuevos riesgos derivados de una urbanización difusa, altamente consumidora de todo tipo de recursos, con crecientes exigencias de movilidad diaria forzada y elevados impactos ambientales que fragilizan su situación.

Al mismo tiempo, la estricta división socio-espacial a diferentes escalas inherente a una lógica mercantil tiende a provocar una segregación que, mediante procesos de atracción-expulsión, concentra aquellos grupos sociales más vulnerables (bajos ingresos, trabajo precario o informal, escasa formación y cualificación profesional...) en determinados territorios mientras los excluye de otros. En consecuencia, la intensidad de los procesos de desposesión (pérdida del empleo, deterioro de las condiciones laborales, devaluación salarial, depreciación de activos inmobiliarios, desahucios, deterioro de servicios y espacios públicos...) no solo será mayor en los territorios más expuestos al riesgo, sino también en aquellos que muestran mayor sensibilidad o fragilidad por la elevada presencia de estos grupos sociales con menores recursos o activos, lo que debilita su capacidad de resistencia. La investigación realizada ha buscado identificar la posible relación de los mayores volúmenes y tasas de crecimiento de las ejecuciones hipotecarias con ambos tipos de situaciones.

\section{Metodología y fuentes de información}

Los procesos de desahucio se han convertido en una de las consecuencias de la crisis que mayor impacto social han causado por afectar a derechos fundamentales y haber alcanzado una dimensión desconocida hasta fecha reciente. No obstante, su estudio se enfrenta a la dificultad que supone una información escasa, procedente de fuentes que la elaboran con criterios heterogéneos y que en la mayoría de casos ha aparecido hace menos de cinco años, lo que no permite analizar en toda su amplitud el impacto de la crisis y comparar lo ocurrido con situaciones anteriores. Por otra parte, esa información se presenta de forma espacialmente agregada, lo que la hace muy poco útil para estudios que se interesan por este fenómeno desde una perspectiva territorial, menos aún para ámbitos urbanos.

Esto es lo que ocurre con tres de las fuentes de información numérica actualmente disponibles. Por un lado, el Colegio de Registradores de la Propiedad edita desde 2013 un informe sobre impagos hipotecarios de vivienda que recoge el volumen total de ejecuciones hipotecarias iniciadas, adjudicaciones de vivienda por ejecución de hipoteca y daciones en pago. También desde esa fecha, el Banco de España comenzó a elaborar una nueva estadística sobre procesos de ejecución hipotecaria de viviendas que en su primera versión se basó en una encuesta dirigida a algunas entidades financieras que aportaron datos sobre las entregas de viviendas realizadas y sobre el hecho de estar o no ocupadas, mientras a partir del segundo informe los datos son aportados por todas las entidades, en cumplimiento de una orden emitida por el Banco de España. Por último, el Instituto Nacional de Estadística inició en 2014 la elaboración de una "Estadística sobre 
Ejecuciones Hipotecarias" que diferencia las correspondientes a fincas rústicas o urbanas y, entre estas últimas, las que afectan a viviendas, solares u otros tipos de inmuebles.

Alguno de los estudios de caso realizados en ámbitos territoriales limitados ha utilizado otros tipos de fuentes de información, bien cuantitativas o cualitativas. No obstante, cuando se busca ofrecer una panorámica de los desahucios en todo el territorio español para identificar claves interpretativas de las notables desigualdades visibles a diferentes escalas, se hace inevitable acudir a las fuentes estadísticas de origen judicial, por ser las únicas que permiten salvar, al menos de forma parcial, las limitaciones temporales y espaciales que aquejan a las mencionadas.

El proceso de desahucio por impago hipotecario es, por lo general, largo y complejo, iniciándose cuando la entidad acreedora, generalmente financiera, promueve por vía judicial una solicitud de ejecución hipotecaria en cualquiera de los juzgados de primera instancia que existen en todos los partidos judiciales. Se definen oficialmente como "aquellos procedimientos que permiten exigir el pago de las deudas garantizadas por hipoteca al acreedor con escritura de propiedad a su favor, debidamente inscrita en el Registro de la Propiedad". Si se resuelve de modo favorable al demandante, el proceso acabará conduciendo en etapas sucesivas hasta la subasta del inmueble y el lanzamiento forzoso de quienes residen en él. Estos últimos se definen como "aquellos actos que generan la entrega posesoria de un inmueble, con independencia del tipo de proceso en que se acuerde, siempre que implique un cambio en su posesión". Ejecuciones hipotecarias y lanzamientos se integran, por tanto, en una cadena de decisiones que solo en una parte de los casos acaban obligando al desalojo, por lo que utilizar unos $u$ otros como referencia conduce a resultados diferentes, tanto en cuanto a su volumen anual como a su significado.

La principal información es la que elabora el Consejo General del Poder Judicial a partir de los datos que los diferentes órganos judiciales remiten de forma periódica y se recoge en la web de la Estadística Judicial (http://www.poderjudicial.es/cgpj/es/Temas/Estadistica-Judicial/). En el caso de las ejecuciones hipotecarias, que son el objeto central de esta investigación, existen datos sobre las ingresadas, resueltas y pendientes desde hace dos décadas y para unidades espaciales a diferentes escalas. Su principal limitación radica en que no distingue el bien hipotecado, lo que supone incluir tanto viviendas (principales y secundarias, ocupadas o vacías) como otro tipo de inmuebles (locales comerciales o industriales, oficinas, garajes...). Por su parte, los datos sobre lanzamientos solo aparecen publicados desde 2008, lo que no permite comparar lo ocurrido en los años de crisis respecto al periodo anterior. Debe señalarse, por tanto, que las ejecuciones hipotecarias no recogen los desahucios provocados por impago de alquileres, muy numerosos pero ajenos al argumento central del artículo que intenta vincular lo ocurrido con los procesos de financiarización y endeudamiento masivo de amplios sectores sociales y territorios.

Finalmente, aunque la información disponible aparece desagregada para las 17 Comunidades Autónomas y las 50 provincias españolas, lo esencial del análisis se ha realizado identificando el comportamiento de los 431 partidos judiciales en que se divide el territorio nacional. Pese a ser de uso poco frecuente, constituye la unidad espacial básica para la administración de justicia, en vigor desde 1834 con pequeñas modificaciones respecto a sus límites. Su interés geográfico radica en que se trata de un área funcional cuyo objetivo fue acercar los juzgados a la población, por lo que su tamaño está en relación inversa a la densidad demográfica y de comunicaciones: en 27 grandes ciudades el partido judicial se identifica con los límites del municipio, en otras 107 de tamaño medio integra hasta cinco municipios, mientras en el resto engloba un número mayor. 


\section{La burbuja hipotecaria y su implosión en España}

Son muchos los estudios que en la última década se han dedicado a la formación en España de una burbuja inmobiliaria sin precedentes desde los años finales del siglo XX y hasta 2007, que cimentó más de una década de crecimiento económico muy superior al promedio de la Unión Europea, destacando sus factores de impulso, así como las estrategias empresariales y los apoyos públicos que la hicieron posible. También sus principales efectos en forma de acelerada ocupación y artificialización del suelo, construcción masiva de viviendas e inmuebles empresariales, junto a un crecimiento especulativo de su precio, todo ello apoyado en una cultura del territorio depredadora, escasamente respetuosa con el patrimonio heredado y poco sostenible a medio plazo, tanto desde una perspectiva económica como ambiental (Fernández Durán, 2006; Burriel, 2008; Naredo, 2009 y 2010; García, 2010; López y Rodríguez, 2010; Romero, 2010; Serrano, 2010; Alguacil et al., 2013; Vinuesa, 2013; Méndez et al., 2015).

Como simple aproximación a la intensidad del fenómeno, baste señalar que entre 1996 y 2006 se construyeron en España algo más de cinco millones de viviendas, con un aumento que supuso pasar de 268.211 viviendas terminadas en la primera fecha a 657.990 una década después $(+145,3 \%)$, o que los visados de obra nueva concedidos por los Colegios de Arquitectos crecieron en esos mismos años de 319.456 a $812.329(+154,3 \%)$, sumando 6,3 millones en todo ese periodo. Su reflejo territorial fue evidente, pues si el censo de 1991 cifraba el parque inmobiliario existente en España en 17,1 millones de viviendas, en 2007 casi alcanzó los 25 millones. Al mismo tiempo, el Observatorio de la Sostenibilidad, trabajando sobre imágenes del proyecto Corine Land Cover, estima que entre 1997 y 2005 la superficie ocupada por tejido urbano continuo y discontinuo, junto a zonas industriales y comerciales, se incrementó en un $34 \%$, lo que equivale a una tercera parte de todo el espacio construido a lo largo de la historia (Observatorio de la Sostenibilidad, 2014).

Cuando se intenta justificar el proceso, algunas interpretaciones ponen el acento en el incremento de la demanda como destacado motor del mismo. Se explicaría por el aumento de la población asociado a un elevado volumen de inmigración exterior, un incremento proporcionalmente mayor del número de hogares al reducirse su tamaño medio, los mayores ingresos derivados de una fase de crecimiento económico, la difusión del mito de la "sociedad de propietarios" entre las clases medias, el desarrollo turístico o la conversión de la vivienda en un bien de inversión con expectativas de alta y segura rentabilidad a corto plazo.

Sin duda estos factores contribuyeron a retroalimentar el proceso una vez iniciado, pero también desvían el foco de atención respecto a la jerarquía de las claves que lo pusieron en marcha y, por tanto, respecto a sus principales responsables. La hipertrofia del sector inmobiliario español no hubiera sido posible sin el paralelo desarrollo de una "burbuja" hipotecaria que alimentó todo el proceso, cuyo estallido provocó el brusco final de la fase expansiva del ciclo inmobiliario y la paralización de la actividad constructiva, así como de un amplio conjunto de industrias y servicios complementarios, desatando una crisis de grandes proporciones. Así pues, la conversión del negocio hipotecario en componente esencial de la actividad financiera convirtió a Bancos y Cajas de Ahorro en principales impulsores de una "máquina de crecimiento" progresivamente descontrolada, que acabó llevando al descarrilamiento al conjunto de la economía española, con elevados costes sociales concentrados también en determinados territorios. 
En un marco de estabilidad monetaria y bajos tipos de interés, reforzado tras la incorporación a la Zona Euro, para lograr los recursos necesarios con que avalar los préstamos la banca española acudió a los mercados financieros internacionales, endeudándose con inversores extranjeros. Con unos salarios reales estabilizados frente al rápido incremento del precio de la vivienda -que en promedio pasó de 771 euros $/ \mathrm{m}^{2}$ en 1997 a 2056 euros en 2006- la captación de demanda solvente se logró a base de acentuar las prácticas de riesgo. El aumento en la proporción del préstamo concedido respecto al precio de tasación, la ampliación del periodo de amortización hasta 30-40 años, o la superación de la relación aconsejable entre importe de las letras e ingresos familiares fueron las más habituales, ante la pasividad de los organismos reguladores (Rodríguez López, 2009). El proceso contó también con apoyo público directo e indirecto mediante la liberalización de los mercados financieros y del suelo, la desgravación fiscal a la compra de vivienda -frente al retroceso en la construcción de vivienda pública-, el olvido interesado de su función social y el progresivo abandono de la ordenación territorial. Como resultado, en 2007 un 87\% de quienes accedían a una vivienda en España lo hacían mediante compra, casi treinta puntos por encima del promedio europeo, con el contrapunto de un endeudamiento privado que alcanzó los 650.889 millones de euros en 2009 según datos de la Asociación Hipotecaria Española y solo recientemente ha comenzado a moderarse tras el hundimiento de ese mercado.

Si se centra la atención en lo ocurrido desde el inicio de este siglo, según la "Estadística Hipotecaria" del Instituto Nacional de Estadística (INE) las 615.703 hipotecas concedidas el año 2001 aumentaron en los siguientes hasta 1.342 .171 en 2006 (+118\%). Al elevarse con rapidez los precios y los valores de tasación, el crecimiento del importe concedido fue aún mayor, pues los 46.547,6 millones iniciales alcanzaron 188.139,1 en 2006, con un incremento del 304\% (Figura No 1). Si se suman los años del gráfico que corresponden a la fase expansiva del ciclo hipotecario, en España se constituyeron 6,7 millones de hipotecas para la compra de vivienda, por un importe total de $853.568,9$ millones de euros y un valor medio que era de 75.600 euros en 2001, pero llegó a 140.324 euros solo cinco años después como reflejo del movimiento especulativo desatado.

Figura $\mathrm{N}^{\circ} 1$

Evolución del número de hipotecas y ejecuciones hipotecarias en España, 2001-2014

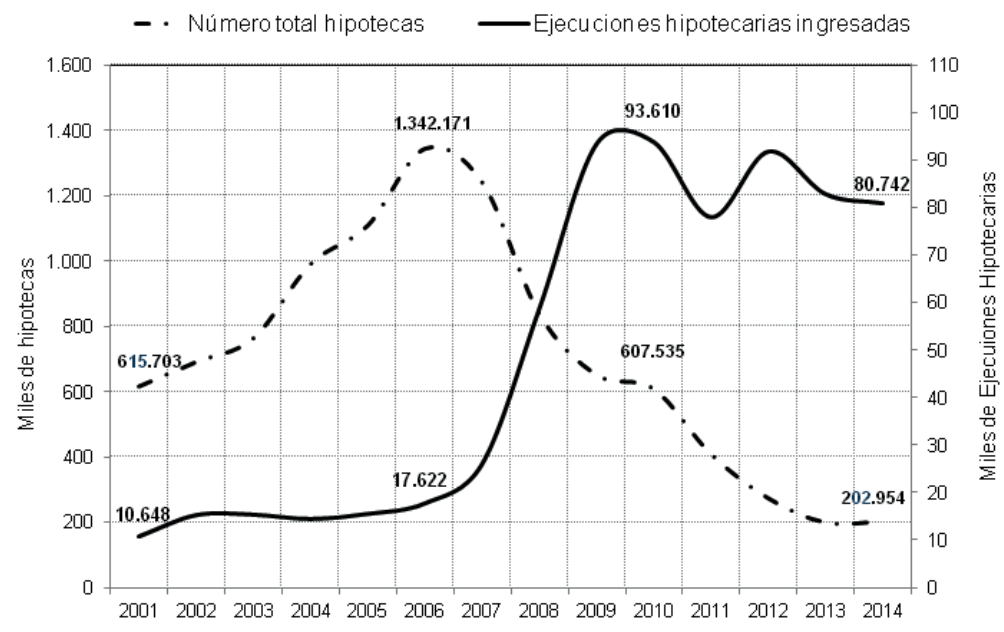

Fuente: INE. Estadística Hipotecaria y Consejo General del Poder Judicial. Estadística Judicial. 
Pero los procesos de financiarización siempre alcanzan sus límites, pese a algunos de sus publicistas o beneficiarios, y la inversión inmobiliaria ha sido históricamente uno de sus puntos débiles (Daher, 2013). A partir de 2007, la creciente dificultad para captar nueva demanda solvente y el significativo incremento de los tipos de interés -el euribor a doce meses pasó del $2,014 \%$ en junio de 2003 al 5,393\% en junio de 2008- provocaron un repunte de la morosidad que encendió las alarmas. La crisis del sistema financiero internacional en septiembre de 2008 -tras el estallido de las hipotecas subprime en Estados Unidos-, las exigencias de los acreedores para recuperar sus préstamos y el traumático saneamiento de un sistema financiero español lastrado, en buena medida, por sus excesos hipotecarios anteriores, originaron una implosión que desestructuró el sistema construido y provocó una brusca contracción del crédito. El número de hipotecas constituidas se redujo desde 1,34 millones en 2006 a 202.954 en 2014 (-84,9\%) y el importe concedido lo hizo en mayor proporción al depreciarse los inmuebles, con un retroceso (20.728 millones en 2014) del $-89 \%$ y un importe medio en torno a los cien mil euros. En el periodo 2008-2014 las hipotecas constituidas se redujeron a 3,2 millones (-52,9\% respecto a los siete años anteriores) y su importe a 379.274 millones de euros $(-55,6 \%)$, pues a los excluidos tradicionalmente del mercado de la vivienda se sumaron unas clases medias empobrecidas y precarizadas, que además encontraron mucha más dificultad para acceder al crédito. La crisis también afectó a Bancos y Cajas de Ahorro debido a la acumulación en sus carteras de créditos de difícil recuperación sobre activos inmobiliarios sobrevalorados; su resultado fue la necesidad de solicitar un rescate con fondos europeos concedido en junio de 2012 por un importe de 62.000 millones de euros, con el aval del Estado y la consiguiente socialización de pérdidas, junto a la desaparición de muchas Cajas o su integración en grupos financieros de mayor dimensión, lo que acentuó la ya elevada concentración del sector.

El nivel de endeudamiento hipotecario alcanzado en los diferentes territorios resultó muy desigual y algo similar ha ocurrido en la fase recesiva del ciclo. No obstante, la información publicada por el INE solo permite constatarlo para la escala de las 50 provincias españolas y sobre hipotecas concedidas para la adquisición de fincas urbanas, que incluye tanto viviendas como solares. En valores absolutos, la polarización en aquellas provincias donde se ubican las mayores aglomeraciones metropolitanas fue el rasgo más significativo, con Madrid y Barcelona que reunieron más de un millón de hipotecas cada una, concentrando casi una cuarta parte $(23,2 \%)$ del total, con un endeudamiento cifrado en 357.000 millones de euros. A estas les siguieron en importancia las provincias de Valencia, Alicante y Málaga, en el litoral mediterráneo, hasta representar entre las cinco mencionadas el $40 \%$ de las hipotecas constituidas y hasta el $45 \%$ del importe total concedido. Por el contrario, si se considera ese importe en relación a la población, los valores más elevados correspondieron de nuevo a provincias mediterráneas, con Girona (45.839 euros por habitante), Málaga (43.783) y Almería (43.722) a la cabeza, donde se desarrolló un turismo vinculado a la construcción masiva de urbanizaciones para segunda vivienda de ciudadanos españoles y de otros países europeos. Pero también a provincias limítrofes con la de Madrid como Guadalajara (46.090) y Toledo (35.131), afectadas por un proceso de urbanización invasivo a medida que se ampliaban los límites de la región metropolitana madrileña para asentar en sus áreas periféricas a grupos de población mayoritariamente jóvenes, con niveles de ingresos medios o bajos, en busca de una vivienda más barata que en áreas más accesibles de la aglomeración. Como contrapunto, las regiones interiores menos urbanizadas y las del litoral atlántico, que mantuvieron economías más diversificadas, con mayor presencia de la industria y menor hegemonía del modelo financiero-inmobiliario, registraron niveles de endeudamiento también inferiores, con un mínimo en la provincia gallega de Ourense (7.670 euros por habitante). 
Lo ocurrido desde 2007 ha invertido esas tendencias, pero manteniendo en lo esencial el mapa anterior, pues si bien las fuertes restricciones al crédito se generalizaron en todo el territorio, los mayores retrocesos correspondieron a las provincias donde había resultado mayor la "fiebre hipotecaria" previa (Figura N²-a1). La mayor disminución en el importe de las hipotecas concedidas con relación a los siete años anteriores se registró en provincias del litoral mediterráneo (Girona, Tarragona, Castellón, Valencia, Alicante, Valencia, Málaga), archipiélagos canario y balear, junto al sur de Madrid (Toledo), y alguna área urbana de intenso crecimiento inmobiliario anterior (Valladolid), con caídas superiores al -90\% en todos los casos. El retroceso más moderado correspondió, en cambio, a provincias donde esa "economía residencial" basada en la construcción de inmuebles e infraestructuras, junto al desarrollo de una amplia variedad de servicios al consumo de baja productividad y empleo muy precario tuvo menor desarrollo, tanto en el interior peninsular como, sobre todo, en el País Vasco.

Figura $\mathrm{N}^{\circ} 2$

Evolución provincial del número de hipotecas constituidas (A1) y ejecuciones hipotecarias (A2), 2008-14/2001-07 (\%).

A 1

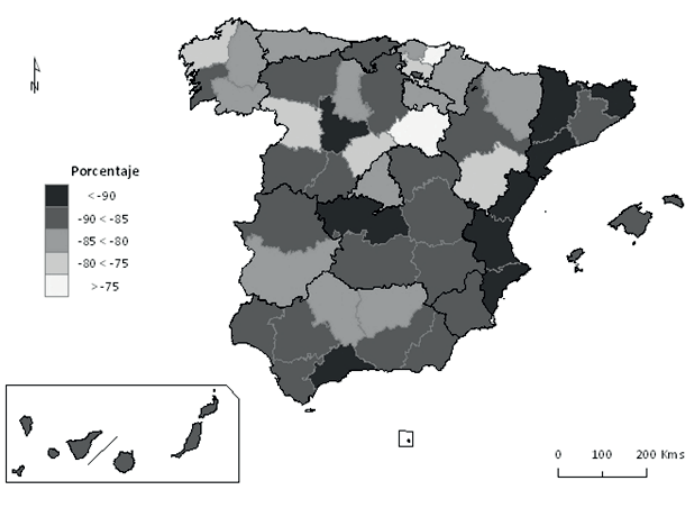

A 2

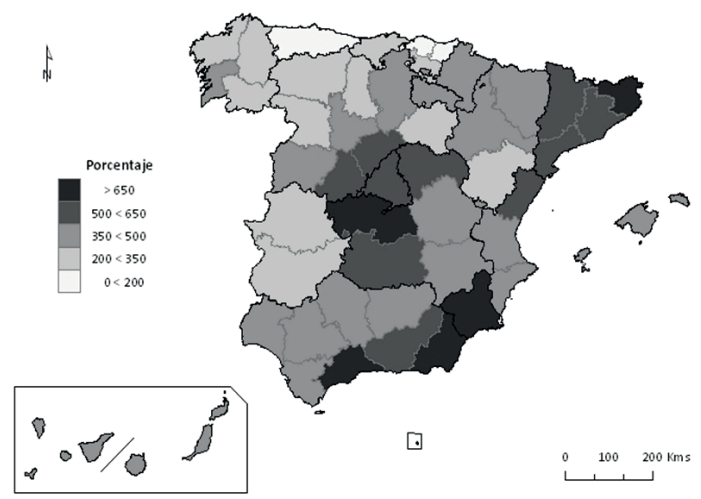

Fuente: INE. Estadística Hipotecaria y Consejo General del Poder Judicial. Estadística Judicial.

\section{Crecimiento y distribución territorial de las ejecuciones hipotecarias: una geografía de la desposesión}

Si el crecimiento incontrolado de los préstamos hipotecarios puso en marcha el engranaje que multiplicó la actividad inmobiliaria y alimentó un proceso urbanizador sin precedentes, el círculo se cerró a partir de 2007 con un aumento también acelerado de los desahucios y la consiguiente desposesión de aquellos sectores de la sociedad más vulnerables. Los efectos de la crisis económica, en particular la pérdida del empleo en el caso de las familias que adquirieron su vivienda en los años de expansión -junto al cese de actividad en empresas que se hipotecaron para adquirir nuevos locales o iniciar su edificación- incrementaron los impagos de las deudas contraídas y con ello los procesos judiciales promovidos por las entidades acreedoras, que se inician con la presentación de una solicitud de ejecución hipotecaria en los juzgados. 
La dimensión y difusión alcanzadas por estos fenómenos de expulsión se convirtieron en componente especialmente visible y traumático de unos procesos que atentan contra el derecho a la vivienda hasta convertirse en un destacado factor de resistencia social ante la ausencia de respuestas suficientes desde las instituciones públicas. La presentación de una iniciativa legislativa popular ante el Congreso de los Diputados en 2012 para reformar la obsoleta e injusta legislación hipotecaria española, junto a la presión de colectivos como la "Plataforma de Afectados por la Hipoteca" (PAH) para buscar fórmulas de negociación con las entidades financieras y buscar alternativas de alquiler social ha ampliado la sensibilización social y política ante esta emergencia habitacional que, no obstante, aún está lejos de encontrar una respuesta suficiente.

La relevancia del fenómeno justifica la aparición de diferentes estudios que lo analizan en el contexto del ciclo inmobiliario y como factor de nuevas formas de segregación territorial y movilización social (Colau, 2012; Colau y Alemany, 2012; Valenzuela, 2013; Díaz Parra, 2014; Méndez et al., 2014; Obeso, 2014; Vives-Miró et al., 2015), caracterizan el perfil de los afectados y los costes sociales derivados (Etxezarreta et al., 2012; Arredondo y Palma, 2013; Human Rights Watch, 2014), o debaten su significado en el plano de los derechos humanos y la propuesta de soluciones legislativas (Defensor del Pueblo, 2012; Valiño, 2013; Rodríguez López, 2014). En un ámbito de investigación emergente, con publicaciones heterogéneas en objetivos, fuentes y escalas espaciales utilizadas, las páginas que siguen permiten ofrecer una panorámica de conjunto, con información temporal y espacialmente desagregada, sobre uno de los indicadores más habituales en el debate social y mediático como son las ejecuciones hipotecarias.

Durante los años del boom inmobiliario, con bajas tasas de morosidad, las ingresadas en los juzgados se mantuvieron en cifras modestas aunque crecientes a medida que también aumentaba el número de hipotecados. De este modo, las presentadas entre 2001 y 2007 sumaron un total de 113.265, con una evolución desde las 10.648 iniciales a las 25.927 del año en que se produjo el cambio de tendencia (Figura $\mathrm{N}^{\circ} 1$ y Cuadro $\mathrm{N}^{\circ} 1$ ). Desde esa fecha y hasta finalizar 2014 la cifra de ejecuciones hipotecarias se ha quintuplicado hasta sumar 577.802 -un 410,1\% de aumento respecto al periodo anterior y un promedio de 226 diarias- con un máximo de 93.610 en 2010, tras producirse el crack financiero e inmobiliario que aumentó en 2,8 millones el número de desempleados en tan solo tres años. Desde esa fecha su volumen anual se ha estabilizado, como reflejo de una presión social creciente, junto a unas medidas legislativas que establecen ciertas restricciones y propician una mayor negociación entre acreedores y deudores, por lo que su volumen anual se sitúa en torno a las 80.000 anuales (80.742 en 2014).

Por su parte, las órdenes de lanzamiento recibidas en los Tribunales Superiores de Justicia en el periodo 2008-2014 sumaron un total de 378.693, lo que equivale a dos terceras partes de las ejecuciones hipotecarias presentadas. No obstante, mientras estas últimas han moderado sus cifras en los últimos años, el número de lanzamientos no ha dejado de crecer (salvo en 2013), por lo que si en 2008 por cada 100 EEHH se contabilizaron 46 lanzamientos, en 2014 esa proporción se eleva ya a 86 , cuestionando así el efecto de las medidas legislativas aprobadas desde 2011 para lograr una mayor protección de los deudores.

En suma, la rápida difusión de esta verdadera "pandemia social" y su gravedad parecen fuera de toda duda. Pero la acumulación de expedientes en unos juzgados con recursos limitados para hacer frente al aluvión recibido añade a lo anterior otro daño colateral. Pese al esfuerzo que supuso pasar de 17.397 ejecuciones hipotecarias resueltas en 2007 a 80.742 en 2014 , las que quedan 
Cuadro $\mathrm{N}^{\circ} 1$

Evolución de ejecuciones hipotecarias (EEHH) y lanzamientos en España, 2001-2014

\begin{tabular}{|l|r|r|r|r|}
\hline Años & EEHH ingresadas & EEHH resueltas & EEHH pendientes & $\begin{array}{c}\text { Lanzamientos } \\
\text { recibidos }\end{array}$ \\
\hline 2001 & 10.648 & 15.762 & 25.473 & \\
2002 & 15.150 & 15.701 & 24.399 & \\
2003 & 15.237 & 17.207 & 23.520 & \\
2004 & 14.346 & 17.271 & 21.743 & \\
2005 & 15.411 & 16.379 & 21.959 & \\
2006 & 17.622 & 16.097 & 25.216 & \\
2007 & 25.927 & 17.397 & 34.015 & \\
2008 & 58.675 & 20.545 & 72.886 & 27.251 \\
2009 & 93.286 & 37.671 & 130.536 & 35.422 \\
2010 & 93.610 & 54.236 & 169.250 & 49.227 \\
2011 & 77.823 & 64.761 & 185.499 & 62.121 \\
2012 & 91.615 & 75.343 & 199.290 & 70.257 \\
2013 & 82.671 & 73.486 & 214.456 & 65.182 \\
2014 & 80.742 & 81.817 & 215.472 & 69.233 \\
\hline
\end{tabular}

Fuente: Consejo General del Poder Judicial. Estadística Judicial.

pendientes al finalizar cada anualidad han crecido de forma espectacular hasta multiplicar en dos veces y media el volumen de las ingresadas (215.472 al finalizar 2014). Eso significa que la maquinaria judicial que tramita estos procedimientos que pueden conducir al lanzamiento tiene combustible acumulado para seguir funcionando a pleno rendimiento en los próximos años, incluso en el caso de que una mejora de la situación económica redujese los nuevos ingresos.

Según muestran algunas de las publicaciones señaladas, las ejecuciones hipotecarias y desahucios han extendido en estos últimos años su área de influencia hasta afectar a segmentos de clases medias empobrecidas, tanto por el efecto de la crisis como de las políticas neoliberales de austeridad con que se respondió en el seno de la Unión Europea. Pero también ha difundido sus efectos por el territorio, aunque con importancia muy variable, tanto si se considera su volumen total como su densidad en relación al número de habitantes o su ritmo de crecimiento desde el inicio de la crisis. La combinación de diversas escalas de análisis permite confirmar que los factores generadores de vulnerabilidad modifican su importancia en cada una de ellas.

A escala provincial, la intensidad del fenómeno en las áreas turísticas litorales se confirma al comparar el volumen de ejecuciones hipotecarias registrado en el periodo 2008-2014 con relación al de ingresadas en los siete años anteriores a la crisis (2001-2007), obteniéndose una distribución de las tasas que muestra regularidades vinculadas en bastantes casos con el descenso relativo en el volumen de hipotecas respecto a las firmadas en la fase expansiva del ciclo (Figura $\left.N^{\circ} 2-A 2\right)$. Se ha afirmado que "el mapa de la crisis es casi exactamente el negativo del mapa de la 'burbuja'" (Burriel, 2014: 106) y la comparación entre estos dos indicadores no hace sino confirmar esa estrecha relación.

En este caso, la provincia de Almería (1.029,3\%) duplicó ampliamente el promedio español de aumento y valores también superiores al $650 \%$ registraron otras provincias mediterráneas (Málaga, Murcia, Girona). Pero igualmente fueron muy elevados los incrementos en las provincias 
metropolitanas de Barcelona y Madrid, desbordando hacia sus provincias limítrofes, lo que apunta la presencia en su interior de grupos sociales altamente vulnerables, concentrados en ciertos sectores de la aglomeración, que están entre los más afectados por los procesos de desahucio. Las provincias que registraron, en cambio, un crecimiento más moderado fueron dos del País Vasco (Vizcaya, Guipúzcoa) y Asturias, todas por debajo del $200 \%$, junto con otras del litoral atlántico o del interior, donde la burbuja hipotecaria no alcanzó los niveles del litoral mediterráneo.

No obstante, estos indicios solo se confirman y matizan cuando se aproxima la lente para observar el comportamiento de unidades espaciales de menor dimensión y heterogeneidad interna como son los 431 partidos judiciales en que se divide el territorio español. La combinación de valores absolutos y de crecimientos relativos entre los siete años de crisis respecto a los siete anteriores permite también llegar a resultados complementarios.

Destaca, en primer lugar, su fuerte concentración espacial (Cuadro $N^{\circ} 2$ ). Más de una cuarta parte (28\%) del total se presentaron en tan solo veinte partidos judiciales, con el de Madrid -que se corresponde con la ciudad capital- muy por encima del resto (25.684 EEHH), seguido por SeviIla, Barcelona y Valencia, también por encima de las diez mil EEHH. Las grandes ciudades, con un mayor parque inmobiliario y número de habitantes, ocupan lógicamente las primeras posiciones con la sola excepción de Bilbao, la capital económica del País Vasco. Pero el hecho de que siete de los diez partidos judiciales con mayor volumen total (salvo Madrid, Sevilla y Zaragoza) y hasta quince de los veinte primeros se localicen en el litoral mediterráneo apunta una tendencia mucho más evidente cuando se consideran las tasas de crecimiento en estos últimos años, especialmente elevadas en tres tipos de territorios que se han mostrado altamente vulnerables por diferentes razones (Figura $\mathrm{N}^{\circ} 3$ ).

\section{Cuadro $\mathrm{N}^{\circ} 2$}

Partidos judiciales con mayor número y tasas de crecimiento en Ejecuciones Hipotecarias

\begin{tabular}{|c|c|c|c|}
\hline Partidos judiciales & $\begin{array}{c}\text { No EEHH 2008- } \\
2014\end{array}$ & Partidos judiciales & $\begin{array}{c}\text { Crecimiento de } \\
\text { EEHH (\%) }\end{array}$ \\
\hline Madrid & 25.684 & Fuengirola & 1340,00 \\
\hline Sevilla & 10.868 & Vera & 1191,71 \\
\hline Barcelona & 10.690 & Ciutadella de Menorca & 1169,23 \\
\hline Valencia & 10.170 & Roquetas de Mar & 898,27 \\
\hline Murcia & 9.020 & San Javier & 894,83 \\
\hline Orihuela & 8.931 & Pozuelo de Alarcón & 894,74 \\
\hline Palma de Mallorca & 8.245 & Estepona & 878,19 \\
\hline Zaragoza & 8.090 & Seu d'Urgell (La) & 871,43 \\
\hline Alicante & 7.958 & Arrecife & 869,54 \\
\hline Málaga & 7.743 & Purchena & 860,32 \\
\hline
\end{tabular}

Fuente: Consejo General del Poder Judicial. Estadística Judicial. 
Un primer conjunto se identifica con la costa mediterránea, particularmente en sus sectores andaluz y murciano (sur y sureste peninsular), que registraron en todos los casos tasas de crecimiento superiores al 500\%. Aquí se localizan los diez partidos judiciales (salvo Pozuelo de Alarcón, en Madrid) que duplicaron con creces el crecimiento promedio de las EEHH en España, con un valor extremo en el caso de Fuengirola (1.340\%), en un espacio turístico masificado como la Costa del Sol (Cuadro $N^{\circ} 2$ ). Son áreas donde promotores inmobiliarios, constructores e inversores, con el apoyo de los gobiernos locales y un planeamiento urbanístico muy permisivo, apostaron por un turismo residencial, que en torno al ocio generó una intensa construcción de urbanizaciones de viviendas destinadas en buena medida a segunda residencia, con un elevado número de compradores y promotores que tras el inicio de la crisis no pudieron hacer frente a las elevadas deudas contraídas. Algo similar ocurrió en otros sectores del litoral peninsular y de los dos archipiélagos (Canarias y Baleares), aunque en volúmenes algo inferiores, pero también aquí el mismo tipo de coaliciones hegemónicas provocó similares excesos urbanizadores. Tanto en los valles del Pirineo catalán como en la sierra madrileña, la proximidad de esas áreas de montaña a una gran aglomeración urbana provocó una presión urbanizadora parecida, seguida de procesos de desposesión no menos importantes en volumen, aunque con un impacto social menos significativo que en los otros dos tipos de áreas, donde la proporción de primeras viviendas parece haber sido bastante superior.

Un segundo conjunto, más disperso y menos extenso que el anterior, corresponde a partidos judiciales identificados con ciudades medias del interior peninsular (Antequera, Calatayud, Aranda de Duero, Lalín, Tomelloso, A Estrada, etc.) que, pese a su heterogeneidad morfológica y funcional tienen algo en común. En estos casos, las estrategias locales de crecimiento durante los años del boom inmobiliario convirtieron la construcción en alternativa a actividades tradicionales que habían sido la base de su economía y se enfrentaban al declive (industrias intensivas en mano de obra como la confección o el mueble, sector agroalimentario, comercio minorista como centros comarcales de servicios en áreas rurales...). La compra de inmuebles también se convirtió a menudo en destinataria privilegiada del ahorro procedente de su entorno rural. Por tanto, también en este caso puede afirmarse que una elevada exposición al riesgo por parte de los actores locales, que condujeron a una especialización residencial y un endeudamiento excesivo, está en la raíz de sus problemas recientes.

Muy distinto es, en cambio, el origen de lo ocurrido en algunos sectores de las periferias metropolitanas, muy visible en los casos madrileño y barcelonés pero también constatado en otras áreas urbanas de menor tamaño (Sevilla, Vigo, Zaragoza, Granada, etc.). Aquí se instalaron familias jóvenes con rentas medias o bajas y empleos a menudo precarios en las numerosas urbanizaciones dispersas que parecían ofrecerles un acceso más asequible a la "sociedad de propietarios" (López y Rodríguez, 2010). En paralelo se produjo una proliferación de parques industriales, comerciales y logísticos, destinados en bastantes casos a pequeñas empresas en busca de bajos costes de instalación. La elevada presencia entre los nuevos residentes de estos grupos sociales y empresas con una elevada sensibilidad o fragilidad ante la crisis explica la especial vulnerabilidad de estos territorios, que se traduce en numerosas ejecuciones hipotecarias y ha dado lugar a lo que algunos calificaron como "paisajes devastados" (Observatorio Metropolitano de Madrid, 2013).

Esta tendencia se hace mucho más evidente al observar con mayor detenimiento lo ocurrido en los partidos judiciales de la región metropolitana de Madrid -identificable en términos adminis- 


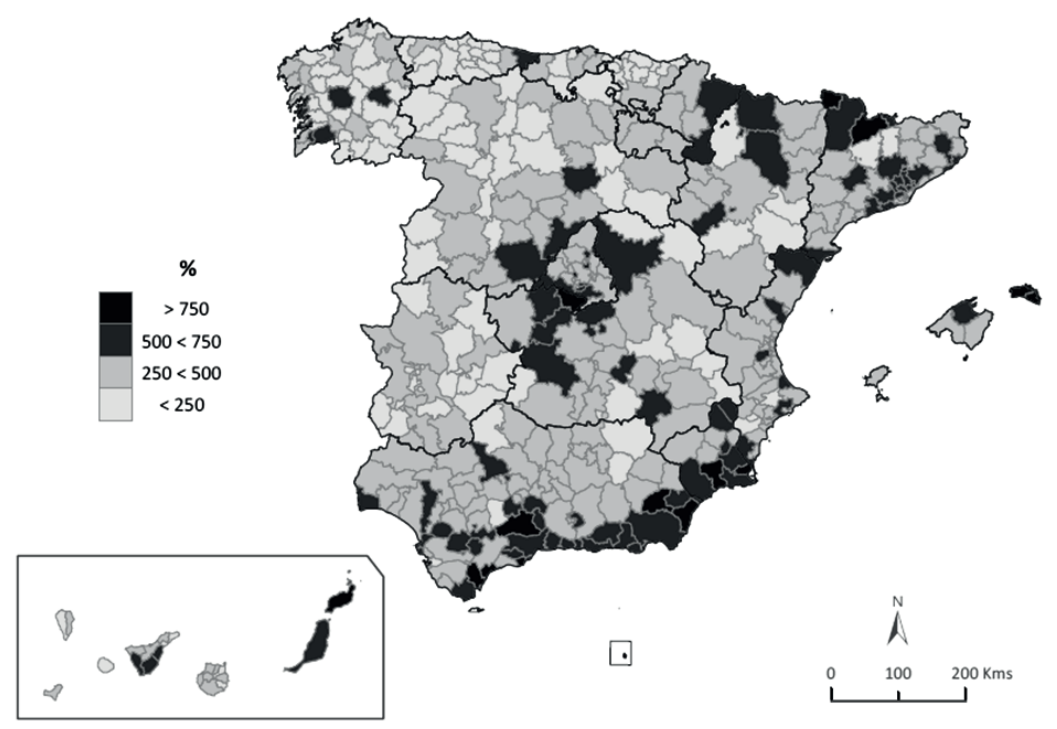

Fuente: Consejo General del Poder Judicial. Estadística Judicial.

trativos con el territorio de su Comunidad Autónoma- y aquellos que la circundan (Figura $\mathrm{N}^{\circ} 4$ ). Sin entrar en precisiones ajenas a los objetivos de un artículo que no puede profundizar en esta escala porque la fuente no ofrece resultados más detallados, pueden destacarse algunas tendencias bastante marcadas y que refuerzan lo dicho anteriormente.

En primer lugar, aunque en ningún caso el incremento de las ejecuciones hipotecarias resultó inferior al $250 \%$, tanto la ciudad central como la mayor parte de las coronas metropolitanas próximas registraron incrementos relativamente moderados con la sola excepción del sector sur. Las tradicionales ciudades obreras e industriales que aquí se localizan, con un parque de viviendas de calidad inferior al del sector noroccidental de la aglomeración, conocieron en las últimas décadas un proceso de terciarización que no modificó sustancialmente su perfil social, manteniendo un predominio de los grupos con niveles de renta, cualificación y calidad del empleo inferiores al promedio, que se reforzaron con la masiva llegada de inmigrantes desde finales del pasado siglo. La ola urbanizadora de las tres últimas décadas extendió sus límites a espacios periurbanos situados más allá de la frontera regional, formando un cinturón externo y un eje de expansión hacia las ciudades de Toledo y Ciudad Real, que recibieron una gran cantidad de nuevos residentes en busca de vivienda más barata y mayores facilidades de pago que están entre los principales perjudicados por la crisis, lo que explica la alta tasa de impagos y el rápido crecimiento de las ejecuciones hipotecarias. Algo similar fue lo ocurrido en la periferia oriental (Guadalajara), mientras que en el sector noroeste la suma de urbanizaciones que también aparecieron en estos años en torno a sus ciudades históricas (Segovia, Ávila) y de segundas viviendas de residentes madrileños justifica los procesos de endeudamiento y posterior expulsión. 
Figura $\mathrm{N}^{\circ} 4$

Crecimiento de las Ejecuciones Hipotecarias en la región metropolitana de Madrid y su periferia

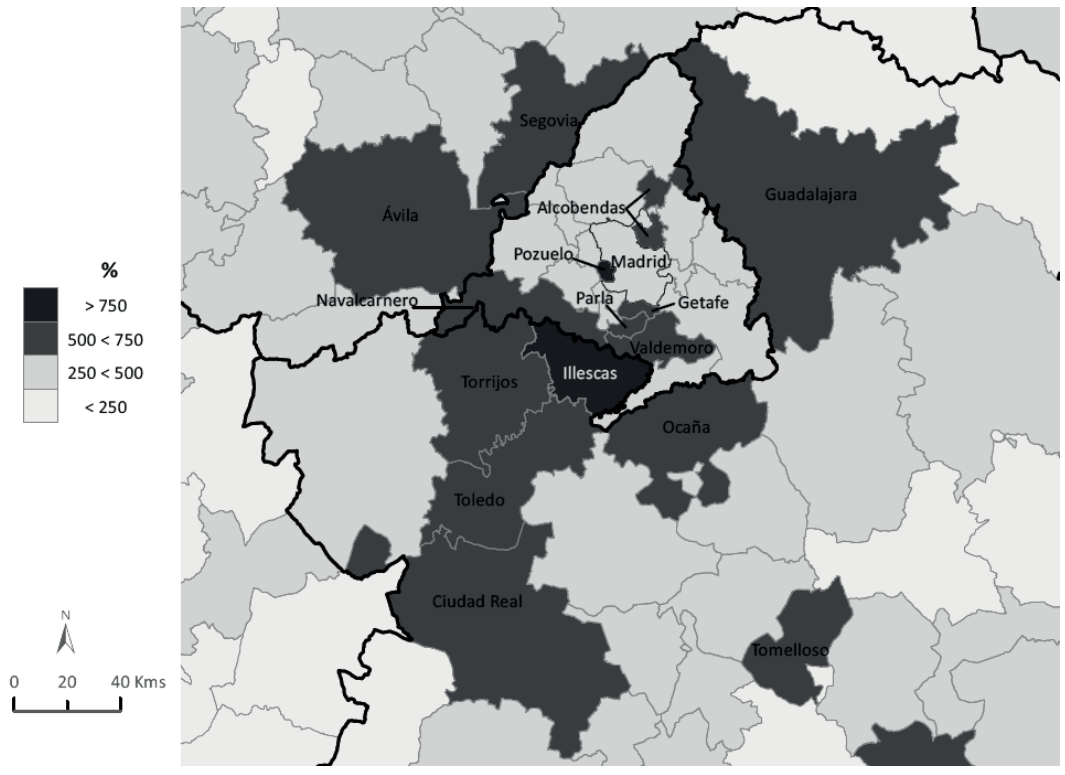

Fuente: Consejo General del Poder Judicial. Estadística Judicial.

En resumen, aunque las cifras aquí manejadas solo alcanzan a bosquejar un drama social como el de los desahucios, alertan sobre la especial gravedad del problema en algunos territorios y propician una interpretación, tanto de las claves que permiten comprender esa desigual distribución como de las responsabilidades de quienes, por acción u omisión, contribuyeron a la insostenibilidad del proceso.

\section{Conclusiones}

El anómalo crecimiento inmobiliario español durante más de una década no puede entenderse al margen del proceso general de financiarización económica, que no solo disoció el aumento descontrolado de los flujos de capital respecto de la economía real sino que también impuso al conjunto de la economía una lógica del beneficio a corto plazo en detrimento de estrategias de innovación y consolidación del tejido productivo que exigen un mayor periodo de maduración. Tampoco sin considerar el reforzamiento en esos años de un bloque hegemónico con destacado protagonismo de los grupos financieros, empresas constructoras y promotores inmobiliarios en frecuente alianza con los diferentes gobiernos de un Estado multinivel, que convirtió el "negocio del territorio" (Herce, 2013) en factor clave de sus elevadas plusvalías y su poder.

El proceso no hubiera alcanzado esa intensidad sin el desarrollo de una "burbuja" hipotecaria de colosales dimensiones, impulsada de forma consciente por unas entidades financieras que convirtieron el negocio inmobiliario en componente central de su actividad. Solo entre 2001 y 2007 se constituyeron más de 6,7 millones de hipotecas por un importe que superó los 853.000 
millones de euros, lo que pone de manifiesto la dimensión de una espiral de endeudamiento, tanto de las entidades financieras españolas con inversores internacionales, como de familias, promotores inmobiliarios y empresas con ellas. En un contexto de rentas salariales estabilizadas frente a un aumento acelerado en el precio de la vivienda -coherente no con una mayor oferta, sino con el mayor crédito disponible- la constante elevación de la demanda solvente para mantener a pleno rendimiento la máquina del crecimiento solo fue posible mediante la generalización de prácticas hipotecarias de riesgo que contaron con la pasividad o aquiescencia de los reguladores institucionales y están en el origen de lo ocurrido a partir del año 2007.

Los desahucios derivados del impago de esa deuda hipotecaria son una de las manifestaciones del final de la fase expansiva del ciclo inmobiliario que mayor impacto social ha provocado, al tiempo que impulsaba diversas formas de movilización y respuesta. Pese a la diversidad de fuentes existentes y las limitaciones informativas que presenta cada una de ellas, la rapidez con que han aumentado esos procesos y sus devastadores efectos en quienes los padecen son conclusiones comunes a todos los estudios publicados. Pero el objetivo de realizar una desagregación territorial de la información y, al mismo tiempo, analizar lo ocurrido en los años de crisis respecto al periodo de crecimiento anterior, obteniendo una panorámica de todo el territorio español para comprobar la desigual intensidad según áreas, obligó a la utilización de fuentes judiciales que por el momento son las únicas que cumplen esos requisitos. En concreto, la investigación se centró en las ejecuciones hipotecarias presentadas en los juzgados de primera instancia localizados en los diferentes partidos judiciales en que se subdivide el territorio español según los datos publicados por el Consejo General del Poder Judicial.

Se confirmó así que, pese a la extensión y generalización del problema, su distribución espacial ha resultado muy selectiva y supone, por tanto, un nuevo indicador de desigualdad entre territorios que, en líneas generales, responde a dos tipos de factores principales. En primer lugar, su gravedad guarda estrecha relación con los excesos cometidos en el pasado reciente y la consiguiente exposición al riesgo asumida en cada caso. Por esa razón, en aquellos territorios donde la actividad inmobiliaria y el nivel de endeudamiento alcanzaron sus máximas cotas -tal como ocurre en la mayor parte del litoral mediterráneo, las islas y las grandes aglomeraciones metropolitanas- el volumen y crecimiento de las ejecuciones hipotecarias también alcanzan sus valores más elevados. Lo mismo ocurrió en algunas otras ciudades donde el esfuerzo de innovación en unas actividades productivas ya en declive se sustituyó por un crecimiento inmobiliario intensivo, para el que el suelo fue la materia prima y el crédito fácil y barato la fuente de energía que pusieron en marcha un proceso especulativo que ha conducido luego a una profunda crisis. Por el contrario, en aquellos otros territorios que mantuvieron una economía más diversificada, en bastantes casos gracias a la presencia de una industria renovada y generadora de demanda para servicios de valor añadido, la menor dimensión alcanzada en su día por la "burbuja" hipotecaria y el consiguiente endeudamiento, junto a la menor incidencia relativa del desempleo producido en la construcción y los servicios al consumo se reflejan en una menor tasa de crecimiento de los desahucios desde el inicio de la crisis.

Pero en el interior de las grandes áreas urbanas también se confirman importantes contrastes asociados a las características sociolaborales de los residentes y su desigual capacidad para enfrentar la crisis del sistema y la desprotección generada por las políticas de austeridad impuestas desde 2010, aunque la fuente utilizada no es la idónea para ese tipo de análisis. En definitiva, el mapa de las ejecuciones hipotecarias suma los efectos de la mayor vulnerabilidad que pade- 
cen determinados grupos sociales con la vulnerabilidad de determinados territorios, fruto de su trayectoria reciente, del modelo de crecimiento característico de cada lugar y de la diversa intensidad con que los gobiernos autonómicos y locales impusieron una racionalidad neoliberal que aumentó los riesgos y al tiempo los concentró en aquellos sectores más desprotegidos de la sociedad y en aquellos territorios con mayores carencias.

Aunque desde el año 2011 se han sucedido hasta cuatro cambios legislativos en España para hacer frente al problema de los desahucios, es evidente que sus resultados están lejos de resolverlo, lo que se acentúa por las resistencias encontradas entre las coaliciones hegemónicas. Algunos de los gobiernos locales surgidos de las elecciones de 2015 han iniciado una acción negociadora y de protección de las familias desahuciadas que ha comenzado a dar sus frutos, pero se necesitan aún cambios legislativos de ámbito general, complementados con acciones específicas en aquellas áreas donde la intensidad del fenómeno acentúa el riesgo de exclusión. Si bien no ha sido objetivo del artículo avanzar en ese terreno propositivo, los resultados obtenidos-complementados con otros posibles en ámbitos más reducidos y mediante el recurso a otro tipo de fuentes- pueden ser de utilidad para apoyar desde los estudios geográficos una acción colectiva en esa dirección.

\section{Referencias bibliográficas}

AALBERS, M. The financialization of home and the mortgage market crisis. Competition \& Change, 2008, Vol. 12, No 2, p. 148-166.

AALBERS, M. The sociology and geography of mortgage markets: reflections on the financial crisis. International Journal of Urban and Regional Research, 2009, Vol. 33; N² 2, p. 281-290.

ALGUACIL, J.; CAMACHO, J. y HERNÁNDEZ-AJA, A. La vulnerabilidad urbana en España. Identificación y evolución de los barrios vulnerables. EMPIRIA. Revista de Metodología de Ciencias Sociales, 2014, No 27, p. 73-94.

ALGUACIL DENCHE, A.; ALGUACIL GOMEZ, J.; ARASANZ DÍAZ, J.; FERNÁNDEZ EVANGELISTA, G.; PANIAGUA CAPARRÓS, J.L.; OLEA FERRERAS, S. y RENES AYALA, V. La vivienda en España en el siglo XXI. Diagnóstico del modelo residencial y propuestas para otra política de vivienda. Madrid: Cáritas y Fundación FOESSA, 2013.

ARREDONDO, R. y PALMA, M.O. Aproximación a la realidad de los desahucios. Perfil y características de las familias en proceso de desahucios en la ciudad de Málaga. Alternativas, 2013, № 20, p. 113-140.

BURRIEL, E. La década prodigiosa del urbanismo español (1997-2006). Scripta Nova. Revista Electrónica de Geografía y Ciencias Sociales, 2008, Vol. XII, № 270(64). Disponible en Internet: http:// www.ub.es/geocrit/sn/sn-270/sn-270/sn-270-64.htm

BURRIEL, E. El estallido de la burbuja inmobiliaria y sus efectos en el territorio. En: ALBERTOS, J.M. y SÁNCHEZ, J.L. (Coordinadores). Geografía de la crisis económica en España. Valencia: Publicaciones Universidad de Valencia, 2014, p.101-140. 
CEPAL. Vulnerabilidad sociodemográfica: viejos y nuevos riesgos para comunidades, hogares y personas. Brasilia: Naciones Unidas, 2002.

COMISIÓN ECONÓMICA PARA AMÉRICA LATINA Y EL CARIBE (CEPAL). Vulnerabilidad sociodemográfica: viejos y nuevos riesgos para comunidades, hogares y personas. Brasilia: Naciones Unidas, 2002.

COLAU, A. La vivienda en España: un derecho por conquistar. En: BELIL, M.; BORJA, J., y CORTI, M. (Editores). Ciudades, una ecuación imposible. Barcelona: Icaria, 2012, p. 113-130.

COLAU, A. y ALEMANY, A. Vidas hipotecadas. De la burbuja inmobiliaria al derecho a la vivienda. Barcelona: Cuadrilátero de Libros, 2012.

CHESNAIS, F. La teoría del régimen de acumulación financiarizado : contenido, alcance e interrogantes. Revista de Economía Crítica, 2003, No 1, p. 37-72.

DAHER, A. El sector inmobiliario y las crisis económicas. EURE, 2013, Vol. 39, № 118, p. 47-76.

DE MATTOS, C. Globalización, negocios inmobiliarios y transformación urbana. Nueva Sociedad, 2007, N²12, p. 82-96.

DE MATTOS, C. Financiarización, valorización inmobiliaria del capital y mercantilización de la metamorfosis urbana. Sociologías, 2016, № 42, p. 24-52.

DEFENSOR DEL PUEBLO. Crisis económica y deudores hipotecarios: actuaciones y propuestas del defensor del Pueblo. Madrid: Defensor del Pueblo, 2012.

DÍAZ PARRA, I. De la gentrificación a la crisis hipotecaria. La geografía de los desahucios en Sevilla a través de las oficinas de asesoría sobre vivienda. Working Paper Series Contested Cities, 2014, N 14005. Disponible en Internet: http://docplayer.es/7089263-Working-paper-series-contested_cities.html

DUMĖNIL, G. y LÉVY, D. La crisis del neoliberalismo. Madrid: Lengua de Trapo, 2014.

EPSTEIN, G. (Editor). Financialization and the World Economy. Cheltenham: Edward Elgar, 2005.

ETXEZARRETA, A.; HOEKSTRA, J.; DOL, K. y CANO, G. De la burbuja inmobiliaria a las ejecuciones hipotecarias. Ciudad y Territorio Estudios Territoriales, 2012, Vol. XLIV, No 174, p. 597-613.

FERNÁNDEZ DURÁN, R. El tsunami urbanizador español y mundial. Madrid: Ecologistas en Acción, 2006.

GARCÍA, M. The Breakdown of the Spanish urban Model: Social and territorial Effects of the Global Crisis. International Journal of Urban and Regional Research, 2010, Vol. 34, No 4, p. 967-980. 
GOTHAM, K.F. Creating liquidity out of spatial fixity: the secondary circuit of capital and the subprime mortgage crisis. International Journal of Urban and Regional Research, 2009, Vol. 33, $\mathrm{N}^{\circ} 2$, p. 355-371.

HACKWORTH, J. The neoliberal city. Governance, ideology and development in American urbanism. Ithaca: Cornell University Press, 2006.

HARVEY, D. Spaces of capital: towards a critical geography. Routledge: Nueva York, 1975.

HARVEY, D. The urbanization of capital: studies in the history and theory of capitalist urbanization. Baltimore: The Johns Hopkins University, 1985.

HARVEY, D. El nuevo imperialismo. Madrid: Akal, 2004.

HARVEY, D. Las raíces urbanas de las crisis financieras: reclamar la ciudad para la lucha anticapitalista. En: BELIL, M.; BORJA, J. y CORTI, M. (Editores). Ciudades, una ecuación imposible. Barcelona: Icaria, 2012, p. 321-358.

HERCE, M. El negocio del territorio. Evolución y perspectivas de la ciudad moderna. Madrid: Alianza Editorial, 2013.

HIDALGO, R. y JANOSCHKA, M. (Editores). La ciudad neoliberal. Gentrificación y exclusión en Santiago de Chile, Buenos Aires, Ciudad de México y Madrid. Santiago de Chile: Pontificia Universidad Católica de Chile, 2014.

HUMAN RIGHTS WATCH. Sueños rotos. El impacto de la crisis española de la vivienda en grupos vulnerables. Washington D.C.: Human Rights Watch, 2014.

KINDLEBERGER, C.P. \& ALIBER, R.Z. Manias, panics and crashes. A History of financial crises. Hoboken: John Wiley \& Sons, 2005.

LAVAL, C. y DARDOT, P. La nouvelle raison du monde. Essai sur la société néolibérale. París: La Découverte, 2010.

LEFEBVRE, C. La révolution urbaine. París: Gallimard, 1970.

LEFEBVRE, H. La production de l'espace. París: Anthropos, 1974.

LÓPEZ, I. y RODRÍGUEZ, E. Fin de ciclo. Financiarización, territorio y sociedad de propietarios en la onda larga del capitalismo hispano (1959-2010). Madrid: Traficantes de Sueños, 2010.

MARAZZI, C. La violencia del capitalismo financiero. En: FUMAGALLI, A.; LUCARELLI, S.; MARAZZI, C.; NEGRI, A. y VERCELLONE, C. (Editores). La gran crisis de la economía global. Mercados financieros, luchas sociales y nuevos escenarios políticos. Madrid: Traficantes de Sueños, 2009, p. 21-61. 
MÉNDEZ, R. Crisis, vulnerabilidad y nuevas desigualdades territoriales en España. Sistema, 2015, No 239, p. $45-63$.

MÉNDEZ, R.; ABAD, L. y PLAZA, J. Geografía de las ejecuciones hipotecarias en España. Estudios de la Fundación $1^{\circ}$ de Mayo, 2014, No 84, p. 1-41.

MÉNDEZ, R.; ABAD, L. y ECHAVES, C. Atlas de la crisis. Impactos socioeconómicos y territorios vulnerables en España. Valencia: Tirant lo Blanch, 2015.

NAREDO, J.M. La cara oculta de la crisis. El fin del boom inmobiliario y sus consecuencias. Revista de Economía Crítica, 2009, № 7, p. 313-340.

NAREDO, J.M. El modelo inmobiliario español y sus consecuencias. Boletín CF+S, 2010, $N^{\circ} 44$, p. 13-27.

OBESO, I. Análisis geográfico de los desahucios en España. Ería, 2014, № 95, p. 327-342.

OBSERVATORIO METROPOLITANO DE MADRID. Paisajes devastados. Después del ciclo inmobiliario: impactos regionales y urbanos de la crisis. Madrid: Traficantes de Sueños, 2013.

OBSERVATORIO DE LA SOSTENIBILIDAD. Sostenibilidad en España 2014. Madrid: Observatorio de la Sostenibilidad, 2014.

PECK, J. y THEODORE, N. Variegated capitalism. Progress in Human Geography, 2007, Vol. 31, № 6, p. 731-772.

REINHARDT, C. y ROGOFF, K. This time is different: eight centuries of financial folly. Princeton: Princeton University Press, 2009.

RODRÍGUEZ LÓPEZ, J. La crisis de los mercados inmobiliario e hipotecario. Factores explicativos. Papeles de Economía Española, 2009, №122, p. 236-253.

RODRÍGUEZ LÓPEZ, J. Ejecuciones hipotecarias. Un año de la Ley 1/2013. Revista de Derecho Civil, 2014, Vol. 1, N³, p. 105-120.

ROMERO, J. Construcción residencial y gobierno del territorio en España. De la burbuja especulativa a la recesión. Causas y consecuencias. Cuadernos Geográficos, 2010, № 47, p. 17-46.

SERRANO, J.M. La edificación de viviendas en España, final del ciclo y ¿ocaso del modelo? Boletín Económico de ICE, 2010, № 2981, p. 37-55.

STEPHENS, M. Mortgage market deregulation and its consequences. Housing Studies, 2007, Vol. 22, No 2, p. 201-220.

STOCKHAMMER, E. Financialization and the Global Economy. Amherst, MA: Working Paper Series, $N^{\circ}$ 240, Political Economy Research Institute, University of Massachusetts, 2010. 
SUBIRATS, J. y MARTí-COSTA, M. (Editores). Ciudades, vulnerabilidades y crisis en España. Sevilla: Centro de Estudios Andaluces, 2014.

VALENZUELA, M. La vivienda tras la burbuja: grandes retos para un futuro incierto en Informe España 2013. Una interpretación de su realidad social. Madrid: Fundación Encuentro, 2013.

VALIÑO, V. (Coordinador). Emergencia habitacional en el Estado español. La crisis de las ejecuciones hipotecarias y los desalojos desde una perspectiva de derechos humanos. Barcelona: Observatorio DESC y Plataforma de Afectados por la Hipoteca, 2013.

VINUESA, J. El festín de la vivienda. Auge y caída del negocio inmobiliario en España. Madrid: Díaz \& Pons, 2013.

VIVES-MIRÓ, S.; GONZÁLEZ, J. y RULLÁN, O. Home dispossession: the uneven geography of evictions in Palma (Majorca). Die Erde, 2015, Vol. 146, № 2-3, p. 79-92. 
